\title{
BEBERAPA CATATAN TENTANG FONOLOGI BAHASA KAMORORAGAM AI'AOWE
}

\author{
Christ Fautngil \\ FKIP Universitas Cenderawasih Jayapura \\ email: chfaut@yahoo.co.id
}

\begin{abstract}
Abstrak
Penelitian ini bertujuan mendeskripsikan aspek fonologis bahasa Kamoro ragam Ai'aowe sebagai salah satu bahasa Papua di Kabupaten Mimika. Metode yang digunakan adalah deskriptif kualitatif dengan pendekatan struktural. Hasil penelitian sebagai berikut. Pertama, bahasa Komoro ragam Ai'aowe memiliki jumlah vokal lebih banyak daripada konsonan. Vokal sebanyak sepuluh jenis, yaitu /i/, /ii/, /e/, /ee/, /a/, /aa/, /u/, / $\mathrm{uu} /$, /o/, /oo/ dan konsonan berjumlah delapan, yaitu/p/, /m/, /t/, /n/, /r/, /w/, /y/, /?/. Kedua, dalam bahasa ini hanya terdapat suku kata terbuka, sehingga hanya ada dua jenis pola suku kata, yakni V dan KV. Tekanan kata jatuh pada suku kata akhir. Ketiga, dalam proses morfofonemik, perubahan verba dipengaruhi oleh persona, kala, dan aspek yang menyebabkan suatu kata bisa bertambah panjang dan bertambah banyak suku katanya. Keempat, bahasa Kamoro ragam Ai'aowe sudah dipengaruhi oleh bahasa dari luar termasuk bahasa Indonesia sehingga ada kecenderungan masuknya fonem-fonem yang bukan asli.
\end{abstract}

Kata kunci: aspek fonologis, konsonan, suku kata, morfofenemik

\section{SOME NOTES ON THE PHONOLOGY OF THE AI'AOWE VARIETY IN THE KAMORO LANGUAGE}

\begin{abstract}
This study aims to describe the phonological aspects of the Ai'aowe variety in the Kamoro language as one of the Papuan languages in Mimika Regency. It employed the qualitative descriptive method using the structural approach. The findings are as follows. First, the Ai'aowe variety in the Kamoro language has more vowels than consonants. There are ten vowels, namely /i/, /ii/, /e/, /ee/, /a/, /aa/, /u/, /uu/, /o/, /oo/ and eight consonants, namely $/ \mathrm{p} /, / \mathrm{m} /, / \mathrm{t} /, / \mathrm{n} /, / \mathrm{r} /, / \mathrm{w} /, / \mathrm{y} /, /$ ?/. Second, in this language there are only open syllables, so that there are only two types of syllable patterns, namely $\mathrm{V}$ and $\mathrm{CV}$. The stress falls on the final syllable. Third, in the morphophonemic process, a verbal change is influenced by the person, tense, and aspect, making a word longer with more syllables. Fourth, the Ai'aowe variety in the Kamoro language is influenced by outside languages, including Indonesian, so that there is a tendency for nonnative phonemes to exist.
\end{abstract}

Keywords: phonological aspects, consonants, syllables, morphophonemic

\section{PENDAHULUAN}

Bahasa Kamoro adalah salah satu bahasa daerah di Kabupaten Mimika Provinsi Papua. Bahasa Kamoro adalah kelompok bahasa-bahasa Papua (Papuan Languages), yakni Filum Pegunungan Tengah (Trans New Guinea Phylum), yang termasuk dalam Stok Tengah Tenggara (Central and South New Guinea Stock), di bawah keluarga bahasa Asmat-Kamoro (Wurm-Hattori, 1981). Berdasarkan laporan-laporan kebahasaan terdahulu, bahasa Kamoro disebut dengan berbagai nama yang berbeda-beda, antara lain bahasa Mimika, bahasa Lakahia, Nagramadu, Mukamuga, Kaokonau, Umari Dua, Neferipi, Maswena. Sebutan tersebut berdasarkan daerah pakai, kelompok sub- 
etnis, dan penyebutan ragam, baik oleh penuturnya maupun oleh peneliti dan orang dari luar.

Daerah pakai bahasa Kamoro cukup luas di wilayah pantai selatan, yakni mulai sungai Opa (134 $45^{\prime}$ Bujur Timur) ke sungai Karumuga (137 $5^{\prime}$ Bujur Timur). Ke arah selatan, bahasa Kamoro terdapat di Teluk Etna sampai sungai Mukamuga (Silzer, 1991). Wilayah ini termasuk Kabupaten Daerah Tingkat II Mimika, Provinsi Papua. Dari 12 distrik di Kabupaten Mimika, delapan distrik berbahasa Kamoro dengan berbagai variasi dialektal. Mungkin saja dalam kampung-kampung tertentu pada setiap distrik itu, penuturnya menggunakan bahasa lain, tetapi secara umum pemakai bahasa Kamoro lebih dominan dalam delapan distrik tersebut. Dengan wilayah pakai yang cukup luas, sudah tentu bahasa Kamoro memiliki cukup banyak variasi dialektalnya, namun sampai saat ini belum pernah dibuat pemetaan variasi ragam-ragam bahasa Kamoro, sehingga belum diketahui secara pasti jumlah dan jenis dialek dan subdialek.

Penulis yang pernah menyebutkan dialek-dialek bahasa Kamoro antara lain Drabe (1953), yang menyatakan bahwa bahasa Kamoro memiliki enam dialek yaitu dialek Westelijk, Tarja, Midden, Kamoro, Wania, dan Mukumuga. Purba (2000) menyebutkan pula bahwa bahasa Kamoro memiliki enam dialek namun berbeda penyebutan namanya dengan penulis terdahulu. Dialek-dialek yang disebutkan Purba adalah dialek Pantai, Koprapoka, Wania, Potoy-Buru, Hiripau, dan Iwaka. Nama yang sama untuk kedua penulis di atas adalah Wania. Tidak dijelaskan pula wilayah pakai setiap dialek dengan berbagai penjelasan.

Salah Satu aspek bahasa Kamoro yang menarik adalah fonologi yang cukup unik dengan fonem-fonem yang sangat terbatas dan pola persukuan yang sangat terbatas pula. Banyak bahasa di dunia memiliki jumlah konsonan lebih banyak daripada vokal, namun bahasa Kamoro ragam Ai'aowe di kampung AyukaTipuka memiliki jumlah konsonan yang sangat terbatas bila dibandingkan dengan vokal.

Berdasarkan keterangan di atas, penulisan ini bertujuan mengungkapkan keunikan-keunikan fonologis bahasa Kamoro ragam Ai'aowe di kampung AyukaTipuka agar dapat dipelajari, diketahui, dan dibandingkan dengan bahasa-bahasa lain. Diharapkan agar keunikan-keunikan fonologi bahasa Kamoro ini, yang merupakan salah satu bahasa Papua, dapat memperkaya khazanah linguistik Nusantara sebagai bagian dari linguistik dunia.

\section{METODE}

Untuk mengungkapkan suatu struktur bahasa sesuai apa adanya pada saat tertentu, sudah tentu metode deskriptif merupakan salah satu pilihan yang tepat. Metode ini mendeskripsikan bentuk dan struktur bahasa berdasarkan keberadaan struktur itu. Dengan demikian, metode yang dipakai dalam penelitian ini adalah deskriptif kualitatif, karena hasil analisis ini memberikan deskripsi keadaan bahasa pada waktu tertentu. Nida (1962: 2) menyebutkan beberapa sifat analisis deskriptif, yakni: (a) descriptive analysis must be based upon what people say, (b) the forms are primary and the usage secondary, (c) no part of a languge can be adequately described without reference to all other parts, dan (d) languages are constanly in the process of change.

Pada dasarnya metode ini menggunakan teknik pengambilan data dengan wawancara berstruktur dan wawancara bebas. Pedoman wawancara berstruktur adalah daftar frasa, klausa, kalimat, dan wacana dalam bahasa Indonesia. Daftar tersebut diterjemahkan secara bebas dengan mengabaikan terjemahan kata demi kata agar diperoleh struktur bahasa Kamoro yang sahih. Wawancara bebas 
dipakai untuk melengkapi data dalam daftar wawancara berstruktur dan latar belakang sosial budaya serta hal-hal lain yang berhubungan dengan bahasa.

Berdasarkan sumber data, penelitian ini tergolong penelitian lapangan (field research) karena peneliti mengambil langsung data primer dari lapangan (Ayatrohaedi, 1979). Sumber pustaka yang digunakan hanya berhubungan dengan informasi awal tentang bahasa Kamoro, situasi kebahasaan, dan informasi penunjang lainnya. Data kebahasaan dari kepustakaan terdahulu tidak dipakai sebab variasi dialektal bahasa Kamoro yang ditulis terdahulu itu berbeda dengan data bahasa Kamoro yang dikaji sekarang ini.

Ragam bahasa Kamoro yang menjadi sasaran penelitian ini adalah variasi dialektal di kampung Ayuka dan Tipuka yang disebut ragam Ai'aowe. Ayuka adalah ibukota Distrik Mimika Timur Jauh dan Tipuka adalah kampung di distrik Mimika Timur. Kedua kampung itu memiliki ragam bahasa yang sama. Penduduk kedua kampung tersebut 95\% homogen.

Informan yang memberi data bahasa terdiri atas tiga orang. Satu informan utama dan dua orang sebagai informan pendamping dan pembanding. Semua informan berjenis kelamin laki-laki yang berumur di atas 30 tahun. Kedudukan mereka sebagai kepala suku sekaligus tokoh masyarakat yang memiliki pengetahuan yang sangat luas tentang bahasa, adat istiadat, dan budaya mereka secara umum (Samarin, 1967).

Data diolah berdasarkan pendekatan strukturalis sehingga akan diperoleh fonem-fonem bahasa Kamoro ragam Ai'aowe di kampung Ayuka dan Tipuka. Pendekatan ini sudah lama dipakai dan dianggap cukup baik untuk analisis fonologi.

\section{HASIL DAN PEMBAHASAN \\ Fonem-Fonem Bahasa Kamoro}

Untuk mengidentifikasi fonem suatu bahasa, pada dasarnya melalui berbagai cara. Salah satu cara yang lazim dipakai adalah kontras bunyi-bunyi bahasa dalam kata-kata tertentu, yang merupakan pasangan minimal (minimal pair) untuk menentukan apakah bunyi itu membedakan arti atau tidak. Pasangan minimal adalah a pair of words in a language which have different meanings but which have identical forms except at one single point. The English words pet and bet have different meanings, ... (Trask, 2007: 170). Bila bunyi itu membedakan arti, sudah jelas adalah fonem dan sebaliknya jika bunyi itu tidak membedakan arti, tentu saja bukan fonem. Kontras seperti itu biasanya pada lingkungan yang identik maupun lingkungan yang analogi.

\section{Kontras Fonem-fonem Vokal}

1) Fonem-fonem Segmental

/a/ - /o/ kontras antara vokoid tengah bawah dengan vokoid belakang atas. Terdapat di awal dan di akhir suku kata.

$\begin{array}{lll}\text { /ama/ } & \text { [a'mEE] } & \text { 'sagu' } \\ \text { /oma/ } & {[\mathrm{T} \text { 'mEE] }} & \text { 'wah!' } \\ \text { /taa/ } & \text { ['ta:] } & \text { 'telur' } \\ \text { /to/ } & \text { ['tT] } & \text { 'ulat sagu' }\end{array}$

/e/-/i/ kontras vokoid depan atas dan depan tengah. Terdapat di awal dan di akhir suku kata.

$\begin{array}{lll}\text { /eka/ } & {\left[{ }^{1} \mathrm{ka}\right]} & \\ \text { /iki/ } & {\left[\mathrm{i}^{1} \mathrm{ki}\right]} & \text { 'duka' } \\ \text { /eme/ } & {\left[\left[^{\prime} \mathrm{m}[]\right.\right.} & \text { 'tifa' } \\ \text { /imi/ } & {\left[\mathrm{i}^{\prime} \mathrm{mi}\right]} & \text { 'jala' }\end{array}$

/a/ - /e/ kontras vokoid pusat bawah dan tengah depan. Terdapat di awal dan di akhir dari suku kata.

\begin{tabular}{lll} 
lawa/ & {$\left[\mathrm{a}^{1} \mathrm{wCE}\right]$} & \multicolumn{1}{c}{ 'mulai' } \\
/ewe/ & {$\left[{ }^{1} \mathrm{w}[]\right.$} & 'buaya' \\
/ama/ & {$\left[\mathrm{a}^{\prime} \mathrm{mEE}\right]$} & 'makanan' \\
/eme/ & {$\left[\left[^{\prime} \mathrm{m}[]\right.\right.$} & 'jala'
\end{tabular}

/ewe/ [[ ${ }^{1} \mathrm{w}[] \quad$ 'buaya'

leme/ [['m[] 'jala' 
/o/ - /e/ kontras vokoid belakang dan tengah depan. Terdapat di posisi awal dan akhir suku kata.

$\begin{array}{lll}\text { /amo/ } & \text { [amT] } & \text { 'keladi' } \\ \text { ame/ } & {[\mathrm{am}[]} & \text { 'rumah' } \\ \text { /opo/ } & {[\mathrm{TpT}]} & \text { 'babi' } \\ \text { /ope/ } & {[\mathrm{Tp}[]} & \text { 'atas' }\end{array}$

2) Fonem-fonem Suprasegmental /e/-/ee/ Kontras bunyi depan-tengah pendek dan panjang

$\begin{array}{lll}\text { lepe/ } & {[[\mathrm{p}[]} & \\ \text { /epee/ } & {[[\mathrm{p}[:]} & \text { 'angit' } \\ \text { /ote/ } & {[\mathrm{Tt}[]} & \text { 'kays' } \\ \text { /otee/ } & {[\mathrm{Tt}[:]} & \text { 'penjolok' }\end{array}$

/u/ - /uu/ kontras bunyi-bunyi belakang atas dengan panjang dan pendek. /pu/ [pu] 'buah' /puu/ [pu:] 'bengkok'

/o/ - /oo/ Kontras bunyi panjang dan pendek untuk vokoid tengah belakang. /oto/ [TtT] 'racun' /otoo/ [TtT:] 'obat'

Masalah suprasegmental dalam bahasa Kamoro, tidak saja diketahui adanya fonem-fonem vokal panjang, tetapi terdapat pula perihal glotal yang sebenarnya merupakan variasi bunyi dari fonem $/ \mathrm{k} /$. Variasi bunyi termaksud disebabkan oleh variasi dialektal. Misalnya, bila pada ra-gam Ai'aowe di kampung Ayuka Tipuka, terdapat glotal pada kata-kata tertentu, dalam ragam Pantai Bahasa Kamoro diduduki oleh fonem $/ \mathrm{k} /$. Berikut diberikan beberapa contoh dalam kata ragam Ayuka - Tipuka dengan ragam Pantai.

$$
\begin{array}{lll}
\text { au'ware - akuare } & \text { 'bahasa' } \\
\text { pi'i } & \text { - piki } & \text { 'pakaian' } \\
\text { era'a } & \text { - eraka } & \text { 'ikan' } \\
\text { ti'aro } & \text { - tikaroko 'pahit' }
\end{array}
$$

\section{Kontras Fonem-fonem Konsonan} /p/ - /t/ kontras bilabial tansuara dan alveolar tansuara.

$\begin{array}{lll}\text { /pi'iri/ } & \text { [pi'iri] } & \text { 'kulit' } \\ \text { /ti'ri/ } & {\left[\text { [ti'ri }^{\prime}\right.} & \text { 'pasir' } \\ \text { /mipi/ } & {[\mathrm{mi} \text { pi }]} & \text { 'ekor' } \\ \text { /miti/ } & {[\mathrm{mi} \text { 'ti] }} & \text { 'udang' }\end{array}$

$/ \mathrm{m} /$ - /r/ kontras bilabial nasal dan getar alveolar.

\begin{tabular}{|c|c|}
\hline /ama/ & {$\left[\mathrm{a}^{1} \mathrm{mCE}\right]$} \\
\hline lawa & {$\left[\mathrm{a}^{1} \mathrm{w} C \mathrm{E}\right]$} \\
\hline$/ \mathrm{mau}$ & [ma'u] \\
\hline /wao/ & [wa'o] \\
\hline
\end{tabular}

$\begin{array}{lll}\text { /mame/ } & {\left[\mathrm{ma}^{\prime} \mathrm{m}[]\right.} & \text { 'mata' } \\ \text { /mare/ } & {\left[\mathrm{ma}^{\prime} \mathrm{r}[]\right.} & \text { 'lidah' } \\ \text { /imi/ } & {\left[\mathrm{i}^{\prime} \mathrm{mi}\right]} & \text { 'jala' } \\ \text { /iri/ } & {\left[\mathrm{i}^{\prime} \mathrm{ri}\right]} & \text { 'jembatan' }\end{array}$

$/ \mathrm{m} /-$ w/ kontras bilabial nasal dan semi vokal dwibibir.

/n/ - /t/ kontras alveolar nasal dan alveolar tansuara.

/tini/ [ti'ni] 'jongkok'

/titi/ [ti'ti] 'gigi'

$/ \mathrm{r} / \mathrm{-} / \mathrm{t} /$ kontras alveolar getar dan alveolar hambat.

$\begin{array}{lll}\text { /oro/ } & {[\mathrm{TrT}]} & \text { 'kau' } \\ \text { /oto/ } & {[\mathrm{TtT}]} & \text { 'racun' }\end{array}$

\section{Fonem Vokal dan Konsonan Bahasa Kamoro \\ Fonem-fonem Vokal}

Berdasarkan hasil kontras vokoid di atas, dapat ditentukan beberapa fonem vokal yang bersifat segmental dan suprasegmental. Untuk fonem vokal yang segmental, terdapat /i/, /ii/, /e/, /ee/, /a/, / aa/, /o/, /oo/ /u/, /uu/. Di sini digabungkan fonem-fonem segmental ditambah dengan fonem suprasegmental, yakni panjang - pendek.

\section{Denah Fonem Vokal Bahasa Kamoro}

Bahasa Kamoro ragam Ayuka - Tipka fonem sebagaimana sudah disebutkan di atas. Fonem-fonem tersebut berikut ini akan dimasukkan dalam Tabel 1 agar jelas tampilannya. Pada Tabel 1 tidak di- 
Tabel 1. Denah Vokal Bahasa Kamoro

\begin{tabular}{lccccc}
\hline & \multicolumn{2}{c}{ DEPAN } & PUSAT & \multicolumn{2}{c}{ BELAKANG } \\
& Pendek panjang & Pendek panjang & Pendek & panjang \\
\hline Atas & i & ii & & u & uu \\
Tengah & e & ee & & & oo \\
Bawah & & & a aa & & \\
\hline
\end{tabular}

sebutkan bagian bulat dan tanbulat, tetapi hanya dicantumkan fonem vokal pendek dan panjang.

Deskripsi Fonem Vokal Bahasa Kamoro

Huruf-huruf vokal biasa terdapat pada puncak di awal, tengah, dan akhir pada silabel. Deskripsi berikut memuat tempat terjadi dan hembusan nafas. Masalah panjang-pendek tidak disebutkan, karena itu deskripsi ini hanya memuat fonem segmental.

/i/ atas depan tambulat dengan udara keluar dari paru-paru, terdapat pada posisi awal, tengah, dan akhir.

$\begin{array}{ll}\text { /ina'o/ } & \text { 'ibu' } \\ \text { /aria/ } & \text { 'buhu' } \\ \text { /titi/ } & \text { 'gigi' } \\ \text { /iwiri/ } & \text { 'bibir' } \\ \text { /iwina/ } & \text { 'manis } \\ \text { /pii/ } & \text { 'pakaian' } \\ \text { /iri/ } & \text { 'empedu' } \\ \text { /miami/ } & \text { 'mandi' } \\ \text { /nai/ } & \text { 'mentah' }\end{array}$

/e/ tengah depan tambulat dengan udara keluar dari paru-paru, terdapat pada semua posisi dalam kata.

$\begin{array}{ll}\text { lepare/ } & \text { 'dagu' } \\ \text { /pea/ } & \text { 'kepiting' } \\ \text { lewe/ } & \text { 'buaya } \\ \text { /eme/ } & \text { 'difa' } \\ \text { /tete/ } & \text { 'kari' } \\ \text { /ote/ } & \text { 'ikan' } \\ \text { /era'a/ } & \text { 'pepaya' } \\ \text { /tena/ } & \text { 'lidah' } \\ \text { /mare/ } & \end{array}$

/a/ bawah pusat bulat dengan udara keluar dari paru-paru, terdapat pada posisi awal, tengah, dan akhir.

$\begin{array}{ll}\text { /awaro/ } & \text { 'pipi' } \\ \text { /watepa/ } & \text { 'belanga' } \\ \text { na } & \text { 'badan' } \\ \text { /awo/ } & \text { 'tetek, susu' } \\ \text { /natani/ } & \text { 'baju' } \\ \text { paara } & \text { 'pagar kebun' } \\ \text { /amaro/ } & \text { 'paman, om' } \\ \text { /tapo/ } & \text { 'mati' } \\ \text { uruna } & \text { 'tombak' }\end{array}$

/u/ atas belakang bulat dengan udara keluar dari paru-paru, terdapat pada posisi depan, tengah, dan akhir.

$\begin{array}{ll}\text { /uupu/ } & \text { 'kecil' } \\ \text { /pura/ } & \text { 'bulan' } \\ \text { /pu/ } & \text { 'masak' } \\ \text { /uwiri/ } & \text { 'anjing' } \\ \text { /arumiri/ } & \text { 'timur' } \\ \text { /aru/ } & \text { 'lipan' } \\ \text { /urai/ } & \text { 'guntur' } \\ \text { /uruna/ } & \text { 'tombak' } \\ \text { /mau/ } & \text { 'kaki' }\end{array}$

/o/ tengah belakang dengan udara keluar dari paru-paru, terdapat pada semua posisi dalam kata.

$\begin{array}{ll}\text { /oro/ } & \text { 'kau' } \\ \text { /tono/ } & \text { 'takut' } \\ \text { /opo'o/ } & \text { 'lalat' } \\ \text { /owena/ } & \text { 'manusia' } \\ \text { /tomo/ } & \text { 'curi' } \\ \text { /pao/ } & \text { 'sukun' } \\ \text { /oto/ } & \text { 'obat' } \\ \text { /owo/ } & \text { 'ulat sagu' } \\ \text { /wao/ } & \text { 'ombak' }\end{array}$


Tabel 2. Denah Fonem Konsonan Bahasa Kamoro

\begin{tabular}{ccccc}
\hline & Bilabial & Alveolar & Alveopalatal & velar \\
\hline Hambat & $\mathrm{p}$ & $\mathrm{t}$ & & $?$ \\
Nasal & $\mathrm{m}$ & $\mathrm{n}$ & & \\
Getar & & $\mathrm{r}$ & & \\
Semi vokal & $\mathrm{w}$ & & $\mathrm{Y}$ & \\
\hline
\end{tabular}

Fonem vokal yang panjang tidak dibuat deskripsi tersendiri sebab pada dasarnya sama dengan fonem-fonem segmental. Hal yang membedakan hanyalah masalah pelafalan panjang dan diisi oleh dua grafem yang sama dan berurutan pada ejaan.

\section{Fonem-fonem Konsonan Bahasa Kamoro Denah Fonem Konsonan}

Bahasa Kamoro di kampung Ayuka dan Tipuka memiliki tujuh fonem konsonan, yang terdiri atas dua fonem hambat, dua fonem nasal, satu getar, dan dua semi vokal. Fonem-fonem konsonan tersebut adalah /p/, /m/, /t/ /n/, /r/, /w/, /y/, /?/. seperti tampak pada Tabel 2.

\section{Deskripsi Fonem Konsonan Bahasa Ka- moro}

Huruf-huruf konsonan biasa terjadi di awal dan di tengah pada silabel, tetapi konsonan tidak pernah terjadi di akhir silabel. Berikut ini deskripsi dari setiap konsonan.

/p/ Hambat bilabial tak bersuara dengan udara keluar dari paru-paru. Terdapat pada posisi awal dan posisi tengah dalam dalam. Tidak terdapat pada posisi akhir karena bahasa Kamoro hanya mengenal suku terbuka, yakni yang diakhiri dengan vokal.

$\begin{array}{ll}\text { /po/ } & \text { 'sayap' } \\ \text { /epare/ } & \text { 'dagu } \\ \text { /pati/ } & \text { 'dada' } \\ \text { /yamapu/ } & \text { 'ketiak' } \\ \text { /pauti/ } & \text { 'pisau' } \\ \text { /tapo/ } & \text { 'mati' }\end{array}$

/t/ Hambat apiko-dental/lamino alveolar tak bersuara dengan udara keluar dari paru-paru. Terdapat pada posisi awal dan posisi tengah kata.
/ta/
/iti/
/tao/
/ote/
/tema/
'telur'
'nyamuk'
'kelelawar'
/watepa/
'kayu'
'tali'
'tempat masak'

/?/ Hambat velar tansuara berupa glotal dengan udara keluar dari paru-paru. Terdapat pada posisi awal dan tengah kata. Dalam ragam ini dapat bervariasi dengan $/ \mathrm{k} /$.

Contoh:

$\begin{array}{ll}\text { /aikaowe/ } & \text { 'nama sub etnis' } \\ \text { /o'o/ } & \text { 'tertawa' } \\ \text { /pi'i/ } & \text { 'pakaian' } \\ \text { /era'a/ } & \text { 'ikan' }\end{array}$

/m/Nasal bilabial bersuara dengan udara keluar dari paru-paru. Terdapat pada posisi awal dan tengah dalam kata. /maemu/ 'air mata' /emae/ 'tulang' /mare/ 'lidah' /yamare/ 'gata-gata' /miami/ 'mandi' /amo/ 'talas, keladi'

/n/ Nasal alveolar bersuara dengan udara keluar dari paru-paru. Terdapat pada posisi awal dan tengah kata. $\begin{array}{ll}\text { /nawaro/ 'pohon beringin' } \\ \text { /uruna/ } & \text { 'tombak' }\end{array}$ 


$\begin{array}{ll}\text { /nima/ } & \text { 'cacing' } \\ \text { /iwina/ } & \text { 'manis' } \\ \text { /napao/ } & \text { 'keringat' } \\ \text { /muni/ } & \text { 'cabai, rica' }\end{array}$

/r/ Getar alveolar bersuara dengan udara keluar dari paru-paru. Hanya terdapat pada posisi tengah dalam kata. Tidak terdapat pada posisi awal.

$\begin{array}{ll}\text { /iri/ } & \text { 'pelangi' } \\ \text { /mare/ } & \text { 'lidah' } \\ \text { /urunal } & \text { 'tombak' }\end{array}$

/w/Semi vokal bilabial bersuara dengan udara keluar dari paru-paru. Terdapat pada posisi awal dan tengah kata.

$\begin{array}{ll}\text { /wapi/ } & \text { 'musuh' } \\ \text { /miwi/ } & \text { 'hantu' } \\ \text { /warao/ } & \text { 'jerat babi' } \\ \text { /atawai/ } & \text { 'ban' } \\ \text { /watari/ } & \text { 'lendir' }\end{array}$

/y/ Semi vokal bersuara dengan udara keluar dari paru-paru. Terdapat pada posisi awal dan tengah kata.

$\begin{array}{ll}\text { /yamapu/ } & \text { 'ketiak' } \\ \text { /(pa)tayaro/ } & \text { 'putih' } \\ \text { /yamare/ } & \text { 'gata-gata' } \\ \text { /mayaro/ } & \text { 'istri sdr lk. Ibu' } \\ \text { /yau/ } & \text { 'matahari' }\end{array}$

\section{Morfofonemik Bahasa Kamoro}

Morfofonemik adalah proses perubahan bentuk yang diisyaratkan oleh jenis fonem atau morfem yang digabungkan. Bahasa Kamoro memiliki cukup banyak bentuk morfofonemik yang dihasilkan oleh proses penggabungan persona dan verba atau adjektiva atau penggabungan kata dengan kata. Sehubungan dengan itu, berikut akan dikemukakan morfofonemik bahasa Kamoro yang dijumpai.

Bentuk morfofonemik akibat proses penggabungan kata ganti persona dengan verba atau adjketiva adalah perubahan bentuk akibat penambahan, penggabungan, pengurangan, dan penyisipan. Sebagai contoh, berikut akan ditunjukkan beberapa bentuk morfofonemik bahasa Kamoro, yang bervariasi dari bentuk dasar.

Perubahan bentuk berikut disebabkan oleh penggabungan persona dengan verba atau adjektiva, yang menduduki fungsi S - P dengan bentuk dasar: maurapae 'duduk'.

Pers. 1 sing. + maurapae $\rightarrow$ maurupau

Pers. 2 sing. + maurapae $\rightarrow$ urupai

Pers. 3 sing. + maurapae $\rightarrow$ maurupa

Pers. 1 dual + maurupae $\rightarrow$ maurupaomo

Pers. 2 dual + maurupae $\rightarrow$ maurupamu

Pers. 3 dual + maurupae $\rightarrow$ maurupami

Pers. 1 pl. + maurupae $\rightarrow$ maurupamo

Pers. 2 pl. + maurupae $\rightarrow$ urupau

Pers. 3 pl. + maurupae $\rightarrow$ maurupae

Bila diamati perubahan bentuk verba maurupae 'duduk' setelah bervariasi bentuknya dalam kaitan dengan persona telah memperlihatkan perubahan bentuk yang dapat disebut sebagai proses morfofonemik, yang dapat dirumuskan sebagai berikut.

Penambahan dasar dengan sufiks, kecuali persona kedua singularis dan pluralis.

$$
\begin{aligned}
\text { maurupa }+ & -\mathrm{e} \rightarrow \mathrm{u} \\
& \rightarrow \text { urupai } \\
& \varnothing \\
& - \text { omo } \\
& -\mathrm{mu} \\
& -\mathrm{mi} \\
& -\mathrm{mo} \\
& \rightarrow \text { urupau } \\
& \text { bentuk infinitif }
\end{aligned}
$$

Perlu dijelaskan di sini bahwa perubahan bentuk dengan penambahan sufiks dan perubahan bentuk dasar dan perubahan seperti diungkapkan itu pada dasarnya berlaku untuk semua verba dan adjektiva. Namun perubahan bentuk itu tidak memiliki pola tetap untuk semua verba dan adjektiva bahasa Kamoro. 


\section{Pola Persukuan Bahasa Kamoro Interpretasi}

Dalam kajian linguistik, terdapat dua semivokal yakni /w/ dan /y/ selalu menjadi bunyi-bunyi yang taksa (ambigue). Bunyi /w/ kadang-kadang diinterpretasikan sebagai satu bunyi, yakni /w/ atau $/ \mathrm{u} /$, atau urutan dua bunyi /wu/ atau/uw/. Demikian halnya, /y/ diinterpretasikan sebagai fonem tunggal /i/ atau /y/ atau urutan /iy/atau/yi/.

Khusus bahasa Kamoro di kampung Ayuka dan Tipuka, ketaksaan dua bunyi tersebut tidak terjadi pada posisi akhir suku kata karena sudah jelas suku kata bahasa Kamoro adalah suku terbuka. Dengan demikian, semua fonem yang menduduki akhir suku kata, pasti vokal, yakni /i/ atau/u/. Urutan dua fonem yakni /yi iy/ dan /wu /uw/ tidak terdapat pula dalam posisi ini. Apabila terdapat bunyi-bunyi seperti itu pada akhir suku kata, sudah pasti akan berbentuk/yi/ dan $/ \mathrm{wu} /$.

Masalah interpretasi hanya mungkin terjadi pada/i/ dan /u/ yang terdapat pada tengah kata, sebagaimana pada contohcontoh berikut ini.

ai.ru 'anak' tidak bisa ditulis ayru, karena tidak ada pola suku kata VK.

miyape 'mengalir' tidak bisa ditulis miape karena lafalnya jelas.

au.wa.re 'bahasa' tidak bisa ditulis aware, karena lafal katanya sebagai [au.wa.re].

tai 'parang' tidak dapat ditulis tay, karena tidak ada pola suku kata KVK.

\section{Pola Persukuan}

Bahasa Kamoro merupakan satu bahasa yang hanya memiliki dua pola suku kata, yakni: V dan KV karena bahasa Kamoro adalah bahasa yang memiliki suku kata terbuka. Berikut diberikan beberapa contoh.
Pola V :

$\begin{array}{lll}\text { /e.me/ } & {[[. ' \mathrm{~m}[]} & \text { 'tulang' } \\ \text { /a.wo/ } & \text { [a.'wo] } & \text { 'tetek' } \\ \text { /i.ri/ } & {[\text { i.'ri] }} & \text { 'gatal' }\end{array}$

Pola KV :

$\begin{array}{lll}\text { /a.ma.re/ } & {[\text { a.mEE.r[] }} & \begin{array}{l}\text { 'kemaluan } \\ \text { laki-laki' }\end{array} \\ \text { ne } & {[\mathrm{n}[]} & \begin{array}{l}\text { 'badan' } \\ \text { mu }\end{array} \\ {[\mathrm{mu}]} & \text { 'kapur' }\end{array}$

Ada pula kecenderungan urutan vokal yang menduduki satu suku kata atau dua suku kata. Dalam hal ini, terdapat dua kemungkinan, (1) apakah vokal itu dilambangkan sebagai penanda bunyi panjang, disebut jangka, dan (2) apakah antara dua vokal diucapkan dengan glotal, entah pada vokal yang sama atau vokal yang berbeda. Khusus untuk vokal yang berbeda, terdapat pula dua kemungkinan, yakni apakah urutan dua vokal atau bunyi luncur (glide).

Permasalahn di atas dapat dijelaskan dengan patokan pada lafal dan penentuan pola persukuan secara teoretis yang telah diterapkan dalam penentuan pola suku kata bahasa Kamoro. Berikut ini diberikan patokan atau ketentuan.

1) Untuk urutan dua vokal yang melambangkan bunyi panjang atau jangka, dikelompokkan sebagai pola suku kata KV dan V.

Contoh:

$\begin{array}{lll}\text { /yaa/ } & \text { [ya:] } & \text { 'arang' } \\ \text { /eraa/ } & {[[. ' r E:]} & \text { 'ikan' } \\ \text { /uuru/ } & {[u: ' r u]} & \text { 'kukuran' }\end{array}$

2) Untuk urutan dua vokal yang di tengahnya diucapkan dengan glotal, dikelompokkan sebagai dua pola suku kata, yakni V.V dan KV.V.

Contoh:

$\begin{array}{lll}\text { /o'o/ } & {\left[\mathrm{T}^{\prime} \mathrm{T}\right]} & \text { 'tertawa' } \\ \text { /a.ma e'e/ } & {[\text { ama['] }]} & \text { 'sagu bakar' } \\ \text { /ina'o/ } & {\left[\mathrm{ina}^{\prime} \mathrm{T}\right]} & \text { 'ibu' }\end{array}$

3) Untuk urutan dua vokal yang bila diucapkan menunjukkan kecenderungan sebagai bunyi luncur, yang bi- 
asanya terjadi pada dua vokal yang berbeda, urutan itu dikelompokkan sebagai bunyi luncur (glide), yang mengikuti pola KV dan V.

Contoh:

$\begin{array}{lll}\text { /e.mae/ } & {[[. \mathrm{ma}[]} & \text { 'tulang' } \\ \text { /nai/ } & {[\text { nai] }} & \text { 'mentah' } \\ \text { /a.ta.wai/ } & \text { [a.ta.wai] } & \text { 'jauh' }\end{array}$

Distribusi Fonem Bahasa Kamoro Distribusi Fonem dalam Suku Kata dan Kata

Berdasrkan pola suku kata sebagaimana telah dibahas di atas, distribusi fonem dalam suku kata, hanya terdapat KV. Karena itu, berikut ini hanya digambarkan kedudukan konsonan dan vokal dalam suku kata.

Tabel 3. Distribusi Fonem dalam Suku Kata

\begin{tabular}{cccccc}
\hline & $\mathrm{i}$ & $\mathrm{e}$ & $\mathrm{A}$ & $\mathrm{U}$ & $\mathrm{o}$ \\
\hline $\mathrm{P}$ & $*$ & $*$ & $*$ & $*$ & $*$ \\
$\mathrm{~m}$ & $*$ & $*$ & $*$ & $*$ & $*$ \\
$\mathrm{~N}$ & $*$ & $*$ & $*$ & $*$ & $*$ \\
$\mathrm{~T}$ & $*$ & $*$ & $*$ & $*$ & $*$ \\
$\mathrm{R}$ & $*$ & $*$ & $*$ & $*$ & $*$ \\
$\mathrm{~W}$ & $*$ & $*$ & $*$ & $*$ & $*$ \\
$\mathrm{Y}$ & $*$ & $*$ & $*$ & $*$ & $*$ \\
$?$ & $*$ & $*$ & $*$ & $*$ & $*$ \\
\hline
\end{tabular}

Gugus, Deret, dan Diftong dalam Bahasa Kamoro

Gugus yang disebut juga dengan kluster adalah urutan fonem-fonem baik konsonan maupun vokal (Kridalaksana: 1993: 70) yang terdapat dalam satu suku kata. Misalnya, kata trak.tor memiliki dua suku, yang terdiri atas trak dan tor. Suku kata trak memiliki gugus, yakni /tr/. Dalam bahasa Kamoro, tidak terdapat gugus konsonan karena pada dasarnya hanya terdapat pola suku kata terbuka, sehingga susunan suku katanya pasti KV.KV. Hal lain yang mempengaruhi tidak adanya gugus konsona adalah dominannya vokal dalam bahasa Kamoro.
Gugus dalam bahasa Kamoro lebih banyak dikaitkan dengan vokal, yakni dengan adanya urutan vokal dalam kata. Berikut diberikan beberapa contoh urutan vokal dalam batas suku kata.

$\begin{array}{ll}\text { /mu.i.ri/ } & \text { 'usus' } \\ \text { /ma.o/ } & \text { 'bapak' } \\ \text { /ao.po.a/ } & \text { 'pemuda' } \\ \text { /ti.a.ro/ } & \text { 'pahit' }\end{array}$

Deret adalah urutan fonem-fonem konsonan yang menduduki batas suku kata. Sebagai contoh, kata empat memiliki dua suku kata, yakni /em/ dan/pat/. Suku kata pertama VK dan kedua KVK. Antara $/ \mathrm{m} /$ dan $/ \mathrm{p} /$ disebut sebagai deret, karena kedua fonem itu menduduki batas suku kata pertama dan kedua.

Gugus dan deret pada dasarnya tidak terdapat dalam bahasa Kamoro, tetapi perlu dikemukakan di sini sebagai satu keunikan yang khusus terdapat pada bahasa ini. Hal ini berkaitan dengan pola suku kata terbuka, yang merupakan pula satu keunikan dalam bahasa Kamoro. Berikut diberikan beberapa contoh yang berhubungan dengan pola suku kata, yang khusus terdapat pada kata yang bersuku dua.

$\begin{array}{lll}\text { V.KV } & & \\ \text { /i.ri/ } & \text { [i.'ri] } & \text { 'jembatan' } \\ \text { /a.ma/ } & \text { [a.'mE] } & \begin{array}{l}\text { 'makanan' } \\ \text { /o.to/ }\end{array} \\ \text { [T.'tT] } & \text { 'obat' } \\ \text { KV.KV } & & \text { 'gigi' } \\ \text { /ti.ti/ } & \text { [ti.'ti] } & \text { 'gigi' } \\ \text { /ma.re/ } & \text { [ma.'r[] } & \text { 'lidah' } \\ \text { /no.ro/ } & \text { [nT.'rT] } & \text { 'saya' }\end{array}$

Urutan fonem yang sangat banyak dijumpai dalam bahasa Kamoro adalah urutan fonem vokal sebagaimana telah dibahas sebelumnya, termasuk di dalamnya diftong. Sehubungan dengan itu, perlu dikemukakan di sini bahwa diftong yang dijumpai secara jelas dalam penelitian ini dapat disebutkan sebagai berikut.

$$
\text { /ai/ } \rightarrow \text { /ai/ 'tuba' }
$$




\begin{tabular}{|c|c|c|}
\hline \multirow{2}{*}{\multicolumn{2}{|c|}{ /atawai/ }} & \\
\hline & & 'jauh' \\
\hline $\mathrm{ao} / \rightarrow$ & $\begin{array}{l}\text { lao/ } \\
\text { /wao/ }\end{array}$ & $\begin{array}{l}\text { 'sarang' } \\
\text { 'ombak' }\end{array}$ \\
\hline & /napao/ & ‘keringkat' \\
\hline$/ \mathrm{ae} / \rightarrow$ & $\begin{array}{l}\text { /paero/ } \\
\text { /namae/ }\end{array}$ & $\begin{array}{l}\text { 'kurus' } \\
\text { 'senang' }\end{array}$ \\
\hline & /mae/ & 'menangis' \\
\hline loe $/ \rightarrow$ & $\begin{array}{l}\text { /apaoe/ } \\
\text { /atoe/ }\end{array}$ & $\begin{array}{l}\text { 'mengunya' } \\
\text { 'cuci' }\end{array}$ \\
\hline
\end{tabular}

Khusus untuk/ae/ dan /oe/, masih diberi beberapa catatan. Pertama, /ae/ dalam beberapa data, dapat ditafsirkan sebagai urutan dua vokal, diftong, atau /æ/. Bila bunyi tersebut termasuk /æ/, tetapi dalam penulisannya tetap dengan urutan /ae/. Untuk /oe/, datanya belum banyak, kecuali dalam kaitan dengan variasi dialektal.

\section{SIMPULAN}

Bahasa Kamoro di kampung Ayuka dan Tipuka memiliki ragam yang berbeda dengan bahasa Kamoro di kampungkampung lain. Ragam mereka disebut bahasa Kamoro Ragam Ai'aowe. Ragam bahasa Kamoro yang lain dan orang luar menyebut mereka Aikaowe, karena ragam mereka hanya mengenal glotal /?/ bukan $/ \mathrm{k} /$.

Jumlah fonem vokal sebanyak sepuluh jenis, yakni /i/, /ii/, /e/, /ee/, /a/, /aa/, /u/,/uu/,/o/, /oo/. Fonem konsonan bahasa Kamoro ragam Ai'aowe sebanyak delapan jenis, masing-masing /p/, /m/, /t/, /n/, /r/, $/ \mathrm{w} /, \mathrm{y} /, \mathrm{l} / \mathrm{l}$

Dalam ragam bahasa ini hanya terdapat suku kata terbuka, sehingga hanya ada dua jenis pola suku kata, yakni $V$ dan KV. Tekanan jatuh pada suku kata akhir. Dalam proses morfofonemik, perubahan verba dipengaruhi oleh persona, kala, dan aspek yang menyebabkan suatu kata bisa bertambah panjang dan bertambah banyak suku katanya. Gugus konsonan tidak ada, hanya gugus vokal dan deret tidak terdapat dalam ragam Ai'aowe ini. Diftong sebanyak empat jenis.
Bahasa Kamoro ragam Ai'aowe sudah dipengaruhi oleh bahasa dari luar termasuk bahasa Indonesia sehingga ada kecenderungan masuknya fonem-fonem yang bukan asli. Dengan demikian, diharapkan agar ragam asli perlu didokumentasikan sehingga kekhususan yang terdapat dalam bahasa itu tetap lestari.

\section{UCAPAN TERIMA KASIH}

Artikel ini diangkat dari penelitian dan penyusunan buku Tata Bahasa Kamoro yang sedang dilaksanakan di Kabupaten Mimika tahun 2012/2013. Kegiatan ini dibiayai oleh Yayasan YuAmako Mimika. Sehubungan dengan itu, ucapan terima kasih yang tak terhingga pertama-tama disampaikan kepada pihak Yayasan Yu-Amako yang diketui oleh Sdr. Agapitus Mairimau, S.Sos dan semua pengurus yayasan termasuk pula para informan di lima kampung, yakni Nawaripi, Koperapoka, Nayaru, Ayuka dan Tipuka. Terima kasih disampaikan pula kepada semua anggota Tim Peneliti termasuk para mahasiswa yang terlibat sejak awal. Akhirnya termia kasih kepada semua pihak yang telah membantu kegiatan penelitian ini.

\section{DAFTAR PUSTAKA}

Ayatrohaedi, 1979. Dialektologi: Sebuah Pengantar. Jakarta: Pusat Bahasa.

Drabbe, P, MSC. 1953. Spraakkunst van de Kamoro Taal. 's-Gravenhage: $\mathrm{M}$. Nijhoff.

Kridalaksana, Harimurti. 1993. Kamus Linguistik. Edisi Ketiga. Jakarta: Gramedia Pustaka Utama.

Nida, Eugene A. 1962. Morphology. Ann Arbor: The University of Michigan Press.

Purba, Th. T. 2000. 'Struktur Bahasa Kamoro.' Laporan Penelitian Pusat Bahasa. Jayapura: Balai Bahasa Jayapura.

Samarin, William. 1967. Field Linguistics. New York: Holt Rinehart and Winston. 
Silzer, Peter J. and Helja Heikinen. 1991. 'Index of Irian Jaya Languages.' Irian Buletin of Irian Jaya XII: 1 - 130.

Trask, R.L. 2007. Language and Linguistics. The Key Concepts. Second Edition. New York: Routledge.
Wurm, Stephen A. and Shiro Hattori. 1981. Language Atlas of the Pacific Area. Canbera: Australian Academy of Humanities. 